\title{
Attitudes of Canadian and U.S. Neurologists Regarding Carotid Endarterectomy for Asymptomatic Stenosis
}

\author{
Seemant Chaturvedi, Jody L. Meinke, Ellen St. Pierre, Bryan Bertasio
}

\begin{abstract}
Background: The American Heart Association carotid endarterectomy (CE) guidelines endorse CE for asymptomatic carotid stenosis if the procedure can be performed with low morbidity. However, the Canadian Stroke Consortium has published a consensus against CE for asymptomatic stenosis. The views of practicing neurologists in the two countries on this subject are unclear. Methods: A survey was undertaken of 270 neurologists from either Florida or Indiana and 180 neurologists from either Ontario or Quebec. Results: The survey was returned by $36 \%$ of neurologists. Both Florida (65\%) and Indiana neurologists $(35 \%)$ were significantly more likely than Canadian neurologists $(11 \%)$ to sometimes/often refer patients for surgery $(\mathrm{p}<0.001)$. Neurologists from Florida relied more on noninvasive methods of carotid stenosis assessment (36\%) than Canadian neurologists $(12 \%, \mathrm{p}=0.003)$, who preferred angiography. Neurologists from Florida more often cited medicolegal concerns as a reason for referring patients for surgery (27\%), compared to Canadian neurologists (3\%, $\mathrm{p}=0.0001)$. Conclusions: Practices pertaining to carotid stenosis evaluation and management differ both regionally and by country. Canadian neurologists refer fewer asymptomatic patients for CE and rely more on angiography as a preoperative diagnostic tool. The potential of medicolegal liability is a greater force in clinical decision-making for certain U.S. neurologists, compared to their Canadian counterparts. These differences may partly explain the variations in CE utilization in the two countries.
\end{abstract}

RÉSUMÉ: Attitude des neurologues canadiens et américains au sujet de l'endartérectomie carotidienne dans la sténose asymptomatique. Introduction: Les lignes directrices de l'American Heart Association sur l'endartérectomie carotidienne (EC) endossent l'EC pour la sténose carotidienne asymptomatique si l'intervention peut être effectuée avec une faible morbidité. Cependant, le Canadian Stroke Consortium a publié un consensus contre l'EC dans la sténose asymptomatique. La vision des neurologues dans les deux pays sur ce sujet n'est pas claire. Méthodes: Une étude a été effectuée chez 270 neurologues de la Floride et de l'Indiana et 180 neurologues de l'Ontario et du Québec. Résultats: Le questionnaire a été retourné par 36\% des neurologues. Les neurologues de la Floride (65\%) et de l'Indiana (35\%) étaient significativement plus susceptibles que les neurologues canadiens $(11 \%)$ de parfois/souvent référer ces patients pour une chirurgie $(\mathrm{p}<0.001)$. Les neurologues de la Floride se fiaient davantage aux méthodes non effractives d'évaluation de la sténose carotidienne (36\%) que les neurologues canadiens $(12 \%, \mathrm{p}=0.003)$ qui préféraient l'angiographie. Les neurologues de la Floride évoquaient plus souvent des préoccupations médicolégales comme motif pour référer les patients à la chirurgie (27\%) par rapport aux neurologues canadiens $(3 \%, \mathrm{p}=0.0001)$. Conclusions: Les pratiques concernant l'évaluation et le traitement de la sténose carotidienne diffèrent selon les régions et les pays. Les neurologues canadiens réfèrent moins de patients asymptomatiques pour l'EC et se fient davantage à l'angiographie comme outil diagnostique préopératoire. Le potentiel de litige médicolégal est une force plus importante dans la décision clinique pour certains neurologues américains que pour leurs collègues canadiens. Ces différences peuvent expliquer partiellement les variations dans l'utilisation de l'EC dans ces deux pays.

Can. J. Neurol. Sci. 2000; 27: 116-119

The practice of carotid endarterectomy (CE) varies substantially between the United States and Canada. These differences involve the volume of procedures performed, the neurologic profile of the patients being operated upon (i.e., percentage of patients who are symptomatic vs. asymptomatic), and the position statements of medical consensus panels in the two nations.

In terms of surgical volume, there are currently approximately 140,000 CE procedures performed annually in the United States. ${ }^{1}$ Recent reports document a substantial upward trend in surgical volume in the US, with a $68 \%$ increase documented in the state of Florida in the years 1995-1996. ${ }^{2}$ By contrast, there are approximately 3000 CEs performed each year in Canada (V. Hachinski, personal communication).

The number of CE patients in the US who are asymptomatic

From the Department of Neurology, Wayne State University/Detroit Medical Center (S.C., E.St.P., B.B.) and the Center for Healthcare Effectiveness Research, Wayne State University/Detroit Medical Center, Detroit, MI, USA(J.L.M.).

RECEIVED DECEMBER 1, 1999. ACCEPTEDIN FINALFORMFEBRUAR Y 14, 2000.

Reprint requests to: Seemant Chaturvedi,Dept. of Neurology, Wayne State University, 8C-UHC, 4201 St. Antoine, Detroit, MI 48201, USA 
is difficult to determine with complete precision, but a recent analysis of CE practices in the state of Ohio revealed that $47.5 \%$ were asymptomatic. ${ }^{3}$ Data from Canada (Alberta and Ontario) reveal that approximately $10-30 \%$ of patients undergoing CE are asymptomatic. ${ }^{4,5}$

Finally, the American Heart Association CE guidelines endorse $\mathrm{CE}$ for asymptomatic stenosis if the perioperative morbidity and mortality are less than $3 \%$ and if the patient has a life expectancy of at least five years. ${ }^{6}$ In contrast, the Canadian Stroke Consortium has published a consensus against CE for asymptomatic stenosis. $^{7}$

We undertook this project to determine the attitudes and practices of neurologists in the two countries on the subject of CE for asymptomatic carotid stenosis. Our hypothesis was that Canadian neurologists would refer fewer patients for surgery and that US neurologists would be more influenced by medicolegal concerns.

\section{METHODS}

A questionnaire was mailed to 180 neurologists practicing in Florida (F), and 90 neurologists practicing in Indiana (I), Ontario $(\mathrm{O})$, and Quebec $(\mathrm{Q})$ (450 surveys in total). A larger number of Florida physicians was surveyed due to the high number of neurologists practicing in that state. A systematic sample of names was chosen from the American Academy of Neurology directory. ${ }^{8}$ The sampling methodology involved selecting every fourth name listed in the state/province listing (every ninth name was chosen for Florida due to the high number of practitioners). No attempt was made to requery initial nonresponders. Surveys were mailed and analyzed during the period March-October 1998.

Florida was chosen due to the documented sharp increase in the $\mathrm{CE}$ volume which has been reported in that state. Ontario and Quebec were selected as the two largest Canadian provinces and Indiana was chosen due to geographic proximity to the Canadian sites.

Questions were posed regarding the following topics:

1) Frequency of patient referral for $\mathrm{CE}$ for asymptomatic stenosis;

2) Methods of preoperative carotid stenosis assessment;

3) Estimation of the local perioperative complication rate;

4) Extent of neurologist involvement in preoperative and postoperative patient evaluation;

5) Influence of medicolegal concerns on the frequency of surgical referral;

6) Knowledge of the risk/benefit ratio for CE in asymptomatic patients.

Statistical comparisons were made using the Chi-square test. Fisher's Exact test was calculated if the expected values were too small to warrant the use of the Chi-square test.

\section{RESULTS}

One hundred and sixty surveys were returned, for an aggregate response rate of $36 \%$. There were no significant regional differences in the response rate $(\mathrm{O} 40 \%, \mathrm{Q} 34 \%, \mathrm{~F} 35 \%, \mathrm{I} 32 \%)$. Responses to the seven items in the questionnaire did not differ significantly between Ontario and Quebec and therefore, the results were combined into a single category of "Canadian neurologists" (C).
Results can be summarized as follows:

1. How often do you refer patients for surgery with asymptomatic stenosis of $>60 \%$ ?

Both Florida and Indiana neurologists were significantly more likely to refer patients, compared to the Canadian neurologists. Details are in Table 1.

2. If you do refer patients for surgery, which methods of carotid stenosis assessment are used preoperatively?

Florida neurologists were significantly more likely than Canadian neurologists to rely on noninvasive methods only prior to surgery. Responses are in Table 2.

3. Do you believe the perioperative stroke and death for asymptomatic patients is less than $3 \%$ at your primary hospital?

Florida $89 \%$ answered yes; Indiana 86\%; Canada $81 \%$ (F vs. $\mathrm{C}, \mathrm{p}=0.23$, I vs. $\mathrm{C}, \mathrm{p}=0.60)$. Among those neurologists who felt the complication rate was $>3 \%$, estimates ranged from 3 $10 \%$. One notable response from a Florida neurologist was that he had requested the perioperative complication data from his hospital on three occasions, with no response from the hospital.

4. Do neurologists examine all patients preoperatively at your primary hospital?

Florida 21\% answered yes; Indiana 7\%; Canada 30\% (F vs. $\mathrm{C}, \mathrm{p}=0.21$, I vs. $\mathrm{C}, \mathrm{p}=0.02$ ).

5. Do neurologists examine all patients postoperatively at your primary hospital?

Florida $16 \%$ answered yes; Indiana 0\%; Canada $15 \%$ (F vs. $\mathrm{C}, \mathrm{p}=0.91$, I vs. $\mathrm{C}, \mathrm{p}=0.06$ ).

6. Are medicolegal considerations a major factor in your clinical decision-making when referring patients for surgery (i.e., a lawsuit against the neurologist if a stroke occurs during medical therapy)?

Florida 27\% answered yes; Indiana 8\%; Canada 3\% (F vs. C, $\mathrm{p}=0.0001$, I vs. $\mathrm{C}, \mathrm{p}=0.29$ ).

Table 1: Frequency of surgical referrals by neurologists

\begin{tabular}{llll}
\hline & Florida & Indiana & Canada \\
Never/seldom & $35 \%$ & $59 \%$ & $89 \%$ \\
Sometimes/often & $65 \%$ & $41 \%$ & $11 \%$ \\
P value (vs. Canada) & $<0.00001$ & 0.0006 & - \\
\hline
\end{tabular}

Table 2: Preoperative carotid imaging

\begin{tabular}{llll}
\hline & Florida & Indiana & Canada \\
Noninvasive methods & & & \\
only (US, MRA) & $36 \%$ & $23 \%$ & $12 \%$ \\
Angiography & $64 \%$ & $77 \%$ & $88 \%$ \\
P value (vs. Canada) & 0.003 & 0.20 & - \\
\hline
\end{tabular}

$\mathrm{US}=$ ultrasound, $\mathrm{MRA}=$ magnetic resonance angiography 
7. According to the Asymptomatic Carotid Atherosclerosis Study (ACAS), how many CE's are necessary to prevent one disabling stroke? ${ }^{9}$

Florida $11 \%$ answered correctly that there was no evidence that disabling stroke was prevented in the ACAS; Indiana $11 \%$; Canada $22 \%$ (F vs. C, $\mathrm{p}=0.09$, I vs. C, $\mathrm{p}=0.21$ ).

\section{Discussion}

The volume of CE performed in the United States and Canada differs to a large degree. In 1995, the rate of CE in adults over age 40 years was 99 per 100,000 in California, 96 per 100,000 in New York, and 38 per 100,000 in Ontario. ${ }^{10}$ Greater availability of surgeons and hospitals performing CE has been offered as one explanation for these utilization patterns. We sought to assess the attitudes of practicing neurologists in portions of the United States and Canada to explore whether differences in neurologist behavior may be contributing to the divergent patterns of $\mathrm{CE}$ utilization.

The first question concerned how often the neurologist referred patients with asymptomatic carotid stenosis for surgery. We found that U.S. neurologists were significantly more likely to refer patients for an operative opinion than Canadian neurologists. Sixty-five percent of Florida neurologists sometimes/often referred compared to $35 \%$ of Indiana neurologists and $11 \%$ of Canadian neurologists. Attitudes of surgeons regarding $\mathrm{CE}$ for asymptomatic stenosis may influence neurologist behavior. For example, in certain parts of Canada, $\mathrm{CE}$ is primarily performed by neurosurgeons and if neurosurgeons are unwilling to operate on asymptomatic patients, neurologist referrals for this procedure will likely decrease. The decreased willingness of Canadian neurosurgeons to operate on asymptomatic stenosis patients is exemplified by the guidelines from the Canadian Neurosurgical Society, where $\mathrm{CE}$ for asymptomatic stenosis was classified as an "uncertain indication", ${ }^{11}$ whereas the American Heart Association characterized this circumstance as a "proven indication". 6

International differences in the use of CE for asymptomatic patients has been previously reported. In a survey of 185 stroke neurologists, $48 \%$ of responding North American neurologists reported recommending $\mathrm{CE}$ for asymptomatic stenosis, compared to $28 \%$ of European neurologists. ${ }^{12}$ This earlier study did not analyze the United States and Canada individually, however, and our study suggests that there is significant heterogeneity between the U.S. and Canada. The increased willingness of U.S. neurologists to refer patients may partly explain the differences in CE utilization in the two countries. International differences in primary care physician behavior in the evaluation of carotid artery disease symptoms has also been documented in the past. ${ }^{13}$

In terms of preoperative imaging, there was a significantly greater reliance by Florida neurologists on noninvasive methods compared to their Canadian counterparts. Overall, however, this remained a minority practice since $64-88 \%$ of neurologists still used angiography. Thirty-six percent of Florida neurologists were content with carotid duplex and/or MRA for preoperative assessment of the stenosis, compared to only $12 \%$ of Canadian neurologists. This difference can be potentially explained by several factors, including pressures in the American health care system to reduce costs, neurologist ownership of ultrasound and/or magnetic resonance imaging facilities, and the recommendations from national experts on this subject. ${ }^{14,15}$ The relative lack of availability of magnetic resonance imaging in Canada may be another factor in the selection of diagnostic imaging tests.

Neurologist involvement in preoperative evaluation of the $\mathrm{CE}$ patient is important since the risk/benefit ratio of $\mathrm{CE}$ differs significantly between patients with symptomatic and asymptomatic carotid disease. ${ }^{16}$ An improper diagnosis of patients with symptoms not referrable to the carotid territory may expose patients to unwarranted surgical risks. ${ }^{17}$ Previous studies have found that nonneurologists overdiagnose many patients with nonfocal symptoms as having had transient ischemic attacks (TIAs). ${ }^{18,19}$ Therefore, it is likely that greater neurologist involvement prior to surgery would lead to more accurate diagnoses and hopefully, referral for CE of only those patients who have been shown in clinical trials to benefit from operative intervention. We found that Canadian neurologists were more often involved in preoperative evaluation of the $\mathrm{CE}$ patient $(30 \%)$ than Indiana neurologists $(7 \%)$, although even in Canada less than one-third of neurologists were uniformly consulted prior to surgery. The concept of neurologist as "gatekeeper" for CE deserves further exploration since at present, only a minority of neurologists are consistently involved prior to surgery.

With regard to postoperative evaluation, there was no significant difference in our study in terms of the frequency of neurologist involvement following surgery in the two countries. In both nations, only a minority of neurologists $(0-16 \%)$ were routinely involved in postoperative care. This may impact the number of perioperative strokes that are detected since a previous review has identified postoperative examination by a neurologist as one of the variables that characterize medical reports with higher levels of morbidity following CE, as opposed to a single surgeon reporting his own results. ${ }^{20}$

We also explored whether medicolegal concerns are a major factor in neurologist decision-making with regard to the $\mathrm{CE}$ patient. We found that $27 \%$ of Florida neurologists cited worries regarding a lawsuit as a reason to refer patients for surgery, compared to only $3 \%$ of Canadian neurologists. The reason for this difference may lie in the high levels of litigation which are pursued in Florida and other features of the U.S. judicial system which are less common in Canada (e.g., contingency fees for attorneys). A comparison of medical malpractice premiums in the United States for internal medicine, used as a surrogate for neurology, reveals that New York and Florida are the two locations with the highest premium rates. ${ }^{21}$ Within Florida, Dade and Broward counties are especially high in terms of the premium levels.

Finally, we investigated whether U.S. and Canadian neurologists were aware of the risk/benefit ratio which has previously been reported in terms of prophylactic carotid surgery in asymptomatic individuals. In the ACAS, no benefit for prevention of disabling stroke was identified. However, only 11$22 \%$ of surveyed neurologists were able to correctly identify this fact. Greater knowledge regarding the risk/benefit ratio may impact the frequency of patient referral by neurologists for surgery. 
As in any study with a survey methodology, our report has inherent limitations including incomplete data accrual. Less than $50 \%$ of neurologists from all four regions responded to the survey, raising the possibility that the practices reported in our study may not be reflective of the majority. In addition, we surveyed only select regions in the two countries and this may limit the generalizability of the study results. Nevertheless, significant variations did emerge in the two countries, which suggest that the findings are not artifactual.

In conclusion, we found that U.S. neurologists were more willing to refer asymptomatic patients with carotid stenosis for surgery than their Canadian counterparts. Differences in clinical practices are not completely unexpected since, as pointed out in a recent meta-analysis, the existing database is somewhat limited and controversial. ${ }^{22}$ Canadian neurologists relied on angiography to a greater extent and were less concerned with medicolegal issues. These differences may partly explain the current variations in $\mathrm{CE}$ utilization in the two countries. Further studies should address other factors which may explain the disparity in CE utilization in the two nations, such as surgeon self-referral and differing reimbursement strategies.

\section{REFERENCES}

1. Huber TS, Durance PW, Kazmers A, Jacobs LA. Effect of the asymptomatic carotid atherosclerosis study on carotid endarterectomy in Veterans Affairs medical centers. Arch Surg 1997; 132: 1134-1139.

2. Huber TS, Wheeler KG, Cuddeback JK, et al. Effect of the asymptomatic carotid atherosclerosis study on carotid endarterectomy in Florida. Stroke 1998; 29: 1099-1105.

3. Cebul RD, Snow RJ, Pine R, Hertzer NR, Norris DG. Indications, outcomes, and provider volumes for carotid endarterectomy. JAMA1998; 279: 1282-1287.

4. Smurawska LT, Bowyer B, Rowed D, et al. Changing practice and costs of carotid endarterectomy in Toronto, Canada. Stroke 1998; 29: 2014-2017.

5. Janes E, Ghali W, Karbalai H, Feasby T, Buchan AM. The risks of inappropriate carotid endarterectomy. Ann Neurol 1998; 44: 510 (abstract).

6. Biller J, Feinberg WM, Castaldo JE, et al. Guidelines for carotid endarterectomy. Stroke 1998; 29: 554-562.

7. Perry JR, Szalai JP, Norris JW, for the Canadian Stroke Consortium.
Consensus against both endarterectomy and routine screening for asymptomatic carotid artery stenosis. Arch Neurol 1997; 54: 2528.

8. American Academy of Neurology 1997-1998 Membership Directory. Minneapolis: 1998.

9. Executive Committee for the Asymptomatic Carotid Atherosclerosis Study. Endarterectomy for asymptomatic carotid artery stenosis. JAMA1995; 273: 1421-1428.

10. Tu JV, Hannan EL, Anderson GM, et al. The fall and rise of carotid endarterectomy in the United States and Canada. N Engl J Med 1998; 339: 1441-1447.

11. Findlay JM, Tucker WS, Ferguson GG, et al. Guidelines for the use of carotid endarterectomy: current recommendations from the Canadian Neurosurgical Society. Can Med Assoc J 1997; 157: 653-659.

12. Masuhr F, Busch M, Einhaupl KM. Differences in medical and surgical therapy for stroke prevention between leading experts in North America and Western Europe. Stroke 1998; 29: 339-345.

13. Goldstein LB, Farmer A, Matchar DB. Primary care physicianreported secondary and tertiary stroke prevention practices. A comparison between the United States and the United Kingdom. Stroke 1997; 28: 746-751.

14. Kent KC, Kuntz KM, Patel MR, et al. Perioperative imaging strategies for carotid endarterectomy. An analysis of morbidity and cost-effectiveness in symptomatic patients. JAMA 1995; 274: 888-893.

15. Barnett HJM, Eliasziw M, Meldrum HE. The identification by imaging methods of patients who might benefit from carotid endarterectomy. Arch Neurol 1995; 52: 827-831.

16. Barnett HJM, Eliasziw M, Meldrum HE. Drugs and surgery in the prevention of ischemic stroke. N Engl J Med 1995; 332: 238-248.

17. Whitty CJM, Sudlow CLM, Warlow CP. Investigating individual subjects and screening populations for asymptomatic carotid stenosis can be harmful. J Neurol Neurosurg Psychiatry 1998; 64: 619-623.

18. Ferro JM, Falcao I, Rodrigues G, et al. Diagnosis of transient ischemic attack by the nonneurologist. Stroke 1996; 27: 22252229.

19. Martin PJ, Young G, Enevoldson TP, Humphrey PRD. Overdiagnosis of TIAand minor stroke: experience at a regional neurovascular clinic. Q J Med 1997; 90: 759-763.

20. Rothwell P, Warlow C. Is self-audit reliable? Lancet 1995; 346: 1623.

21. Medical Liability Monitor. 1998; Volume 23. Glenview, IL.

22. Benavente O, Moher D, Pham B. Carotid endarterectomy for asymptomatic carotid stenosis: a meta-analysis. BMJ 1998; 317: 1477-1480. 